\title{
Introducing a Practical Method to Reduce Rural Traffic Accidents Near Iranian Cities
}

\section{Jalil Shahi, Mortaza Khalili*}

Department of Transportation, Iran University of Science and Technology, Tehran, I.R. Iran.

Study Area:Tehran, Iran

Coordinates: $4^{\circ} 24^{\prime} 36^{\prime} \mathrm{S} 37^{\circ} 10^{\prime} 48^{\prime} \mathrm{E}$

Key words: Highway bypass; Suburban way, Delphi method

\section{Abstract}

As per the available statistics of accidents on suburban roads, especially near the cities, effective methods for reducing accidents which finally lead to the frequency and severity reductions of accidents has been identified. This paper deals with the bypasses planning problem. Further to the study and investigation on the effective criteria in bypasses optimization, it is attempted to seek solution upon which, one could choose the best option among the few proposed options of the bypasses without involving in any of the above-mentioned problems and with the appropriate construction cost. Road accidents must be considered as the most important criterion in designing and decision making the support system for the bypasses optimization. Thus, it has been attempted here to focus on developing a model as a major issue of decision about the bypasses.

foundation. Pates (Pates, 1999) proposed the idea of separating urban ways from the crossing traffic and also traffic pacifying in Denmark and named them as silent roads regarding the above-mentioned idea and their performance. The Danish road directorate (DRD) released a booklet in the 1980s indicating how the rapid crossing traffic could be slowed down in urban areas (Willumsen, 1981). Also in 1990, the traffic planning was organized by DRD in the vicinity of cities to separate passing fast cars from the slow urban traffic (Bendsen, 2017).

During 1960 and 1970 decades in Finland, special places were considered for pedestrians and cyclists besides the roads passing through the cities for reducing the number and severity of accidents. Also in 1980s, roads passing through small towns were designed taking the environmental status of these cities and safety prediction into consideration just to increase the safety of citizens. In 1990 in Finland, several studies were carried on the performance of the ways which had been constructed decades ago and an instruction was spread out in 1993 by the bureau responsible for the ways' management of this country titled as passing roads status improvement through small towns (Christopher \& Sorin, 2011).

In 1990s, the bureau of ways of Norway (NPRA), designed passageways with minimal environmental effects for 6 selective cities. Solutions were made for improving the main passages and bypasses were made in the greater residential centers. This set of actions and first came to the power and resulted in the bypasses 
attitudes with the passing traff ic through residential areas are classified into 4 groups including a new way construction as a bypass, the main road passing through the city, the main road passing through the residential sections and a combination of the first and third cases (Pates, 1998).

In smaller towns, one can avoid such theories due to the problems related to the land ownership and high expenses of bypass construction. During the 1960 and 1970 decades in US, investigations were done on the founded bypasses effects in order to assess the economic and environmental influences and their effects on the land use changes, land value, etc. (US.FHA, 1980; Vockrodt, 1967). All of such studies performed on the bypasses during the last 30 years resultant to an important and common point and that was the requirement of proper design and planning for reducing their possible negative consequences and optimizing their usage.

If a bypass is formed nearer to the city, the possibility of its usage by the local traffic of the city becomes more. It is needless to say that the amounts of constructions near the bypass lands, connectivity to the city and other negative impacts on them, have inverse proportion with the distance between the city and bypass. Talthough the proximity of bypass to the city may lead to its smaller length and reduce its construction expenses, but it is important to note that the land value is higher near the cities and this can nullify the possible savings in terms of the reduced length. However, it should be said that the bypass construction in the far distance could cause an added value of the lands between the bypass and city.

\section{Methodolgy:}

Various countable and non-countable variables must be involved in the planning as well as be optimizing the bypasses which have been illustrated in the following paragraphs during an example solution for Qeshm city. For the noncountable variables and factors, it is first attempted to weight them and make them

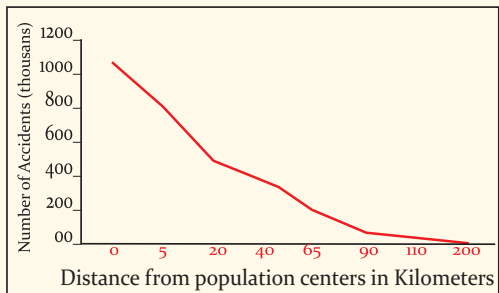

Figure- 1: Road accidents Vs the distance from population centers. countable by using the

Delphi method and then include them in a hierarchical structure for the decision making (Fig. 2). Accidents are the most important one of these variables. Accidents are caused by the human factors (such as driver carelessness), weakness of the way's components and geometry (such as inadequate curve radius), factors related to the characteristics of the vehicle and passing traffic, climatic factors, etc.

Various models are availably capable of predicting the number of possible accidents. But, most of such models may not be implemented in this research due to the different driving condition in Iran. Moreover, the statistics of Iran's accidents or their analysis are generally unavailable or if it is partially and irregularly scattered in the references, no address or full specification could be picked-up from them (Farzipour, 2010).

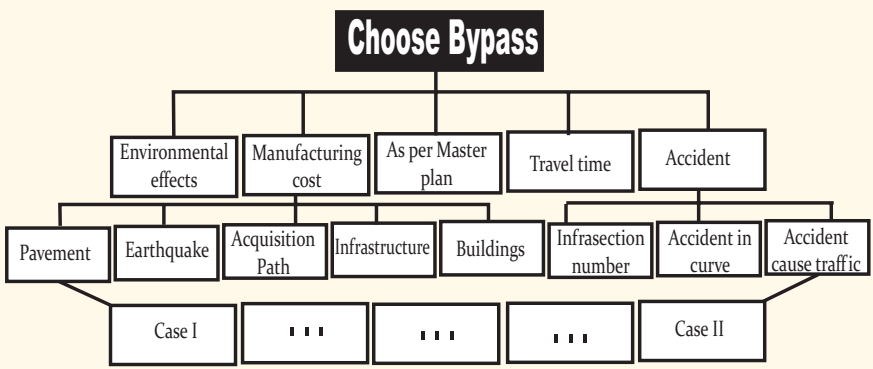

Figure-2: The hierarchical structure of bypass selection

The accident criterion in the bypass selection could be sub-divided into three sub-criterions. As shown by the hierarchical structure graph, these sub-criterions include the accidents in the curves, accidents due to the traffic volume and condition and the number of intersections. The estimation of road accidents expenses is a complicated work. Ayati (2005) suggested six methods for this but they are out of the scope of this study. However, one can estimate that by having the number of predictable accidents in each option and the average cost of each accident. Therefore, the number of predictable accidents in each option has been chosen as a criterion. In this report, the accidents in the curves are calculated from the following relation:

$$
\mathrm{A} 1=(\mathrm{r} . \mathrm{L}+.0336 \mathrm{D}) \mathrm{V}
$$

In which ' $\mathrm{D}$ ' is the curve degree and ' $\mathrm{V}$ ' stands for the velocity of plan. ' $r$ ' in the above equation is the rate of road accidents stated in terms of million vehicles-kilometer. Farzipour (check it) calculated this value for the passages of city margins in Iran and these values are used for the presentstudy.

Accidents caused by the traffic conditions are governed by the following relation

$$
\mathrm{A}_{2} \alpha(\text { flow })^{\beta 1} \text { (capacity) }{ }^{\beta 2}
$$

which deduced from the previous studies and its parameters are examined and calibrated as well. The reason of choosing these two relations in the final model is the lack of sufficient statistics and information about the necessary variables for the other relations cited in Iran. Eq. (2) has been analyzed by Mont Carlo method and its obtained results have been verified for Iran's conditions. Fig.-2 depicts the sensitivity value of Eq. (1) than the coefficient of 0.0366 . As can be observed, with an increment of 3000 percent in this coeff icient's value, only 20 accidents are added to the number of accidents in a curve with the radius of 50m. Therefore, Eq. (1) can be implemented with the proper approximation for estimating the accidents in the curves. Since the number 


\section{TECHNOSCIENCE ARTICLE}

of intersections with the same level, affect the number of accidents (Ayati, 2005), this factor is also considered as the accident criteria. The method is that the homonymous criteria in the hierarchical process are mutually compared and the comparative matrix is formed whose components are the fractions resulted from the division of the weight values of these two criteria. When calculating the final weight, the effect of each criterion in the final selection is estimated by giving importance coefficient for each criterion and comparing it with other criteria involved in the choosing. However, as illustrated by Ayati (2005) that nearly $40 \%$ of road accidents in Iran occur at intersections with the same level, the importance coefficient of an intersection rather than an accident is considered to be o.4. The position of the intersections' number criterion in the bypass selection hierarchical chart is shown in Fig. 2.

This parameter is calculated by Eq. (3) for each bypass and of course, one can estimate the accidents expenses by having the number of accidents and the average cost of each. However, due to the capability of the analytical hierarchy process (AHP) in evaluating various options with having the heterogeneous criteria, one could be able to use the number of predictable accidents in each variant as the measuring criteria instead of the accidents costs. Because the number of accidents is directly depending on the average cost of all the accidents and since the hierarchical process uses the criteria comparison technique, it has the capability of considering the accident's number parameter as a comparative tool between two or more variants.

$$
\text { del ACC }=\left(\mathrm{ACC}_{1}+\mathrm{ACC}_{2}\right)-\mathrm{ACC}_{3}
$$

In the above relation, the number of accidents in the curves is analyzed using Mont Carlo method and the sensitivity analysis of this model and it does not differ for Iran's condition. The number of accidents due to the traffic condition is also governed by Eq. (4). Here, $\mathrm{ACC}_{3}$ describes the annual number of accidents happening in the margin of a city without any bypass.

$$
\left.\mathrm{ACC}_{2}=\mathrm{P}=\alpha(\text { flow })^{\beta 1} \text { (capacity }\right)^{\beta_{2}}
$$

In order to be sure about the accuracy of the results of the designed model, they must be first verified (Saaty, 1980). The validation of the models made up of the AHP method is stated by the incompatibility rate calculation whose value should not be greater than o.1. The only difference between the verification method of AHP based models and the other ones is that the verification process should be performed for each problem-solving stage (HCM, 2010). This work is done here for a case study.

The most important statistics and data used in the present research are the data and specifications related to the accidents in the urban ways network of the country. Providing the accidents related statistics and generally any statistical information in Iran is faced with several difficulties and if it is not impossible, it would be too much
Ambient Science, 2018: Vol. 05(1); 17-21 DOI:10.21276/ambi.2018.05.1.ta01

complicated. Regarding the accidents information used in the present report, several organizations were referred to and finally, the necessary statistics were provided by the cooperation of the safety off ice of the transportation and terminals organization. The mentioned statistics are provided based on two points. First, due to the existence of all three modes of hills, plain and mountainous in Iran's ways, the annual accidents statistics are achieved for all three cases. The second point is that only the statistics of road accidents in the vicinity of cities are considered because the majority of road incidents happen in the interval of 25-30 kilometers from the entrance and exit of the cities.

Table-1 lists the correction factor, for the traffic distribution on both sides of a piece of the way (Hauer, 2014). The capacity of the passageway is calculated as:

$$
S f=2800(v / c)_{i}-f_{d}-f_{w}-f_{h v}
$$

where, $S \_f$ is the capacity of the passageway (pcu/hr), denote the correction coefficients corresponding to the traffic ratio in each direction, width, and heavy vehicles, respectively and stands for the ith service level (A or B or C, etc.). In this relation, the directional distribution is assumed to be equal for both directions and is obtained by:

$$
f_{h v} \frac{1}{1+p_{t}\left(E_{t}-1\right)+p_{B} B\left(E_{B}-1\right)+p_{R}\left(E_{R}-1\right)}
$$

In which, $E_{t}, E_{B}, E_{R}$ are the conversion coefficients of heavy vehicles in terms of private vehicles and describe the ratios of these vehicles. Tables $2 \& 3$ give the parameter values used for the above relations (Hauer, 2014).

Table 1 . The correction coefficient for the traff ic distribution in both sides of a piece of way

\begin{tabular}{lllllll}
\hline $\mathrm{POD}^{* *}$ & $50-50$ & $40-60$ & $30-70$ & $20-80$ & $90-10$ & $100-\mathrm{o}$ \\
$\mathrm{CF}^{*}\left(f_{d}\right)$ & 1.0 & 0.94 & 0.89 & 0.83 & 0.75 & 0.71 \\
\hline
\end{tabular}

** Percent orientation distribution; ${ }^{*}$ Correction factor

Table 2. The equivalent values of driving for truck, autobus and recreational vehicles for the overall cut of the way

\begin{tabular}{lllll}
\hline Vehicle type & Level of service & Flat & hills & Mountainous \\
\hline \multirow{3}{*}{ Truck $\left(E_{T}\right)$} & $\mathrm{A}$ & 2 & 4 & 7 \\
& $\mathrm{~B}, \mathrm{C}$ & 2.2 & 5 & 10 \\
& $\mathrm{D}, \mathrm{E}$ & 2 & 5 & 12 \\
\hline Recreational & $\mathrm{A}$ & 2.2 & 3.2 & 5 \\
$\left(E_{R}\right)$ & $\mathrm{B}, \mathrm{C}$ & 2.5 & 3.9 & 5.2 \\
& $\mathrm{D}, \mathrm{E}$ & 1.6 & 3.3 & 5.2 \\
\hline \multirow{3}{*}{ Bus $\left(E_{B}\right)$} & $\mathrm{A}$ & 1.8 & 3 & 5.7 \\
& B,C & 2 & 3.4 & 6 \\
& $\mathrm{D}, \mathrm{E}$ & 1.6 & 2.9 & 6.5 \\
\hline
\end{tabular}

Table 3. The numerical values of service levels in different conditions of the way

\begin{tabular}{llll}
\hline Area & Flat & hills & Mountainous \\
\hline Level of Services & $\mathbf{1 . 0 0}$ & 0.9 & $\mathbf{0 . 8 2}$ \\
\hline
\end{tabular}

Regarding the above-mentioned matters and by dividing the way into the 5 -kilometer parts, the 
relationship among the number of annual accidents per route kilometer, a volume of the crossing traffic and capacity can be deduced as below:

$$
\left.P=44391.8(\text { flow })^{0.626424} \text { (capacity) }\right)^{-2.082873} \quad \text { (7) }
$$

To obtain the above relation, first, Eq. (8) is chosen according to the previously studied models and relationships in the field of accidents prediction in the future communicative axes. This is mainly due to the availability of its data which makes working on it more eff icient.

$$
P=\alpha(\text { flow })^{\beta_{1}}(\text { capacity })^{\beta_{2}}
$$

Here, $\alpha, \beta 1$ and $\beta 2$ are the calibration coefficients. Then, the statistics related to the number of road accidents ( $P$ in the above equation) happened in the distance of 30 kilometers from several cities of Iran are collected from Iran's transportation and terminals organization (Farzipour, 2010). Regarding the inaccurate registering method of the accident location, this 30kilometer distance is divided into 5-kilometer parts whose first part is begun from the kilometer 2.5 of each axis from the city side. Due to the existence of irregular traffic and mixture of the urban traffic with the road one, the statistics corresponding to the accidents between kilometers zero and 2.5 are discarded from the computations. Meanwhile, the annual traff ic volume is deduced for each 5-kilometer part of each axis and the axis capacity is evaluated. For each 5-kilometer part of each axis, the number of accidents per kilometer is estimated. Now, the above values for each part of each axis are input into Eq. (7) and the logarithm is taken from both sides of this relation. Therefore, Eq. (7) is transformed to a 3-variable linear relationship which can be implemented for obtaining the values of form a simple 3 -variable linear rounding technique. The standard errors of and are calculated as 0.035 and 0.0128 , respectively. Furthermore, the correlation coeff icient of variables is estimated as 0.83 .

\section{Results and discussion:}

The Delphi-hierarchy method is implemented here for choosing the optimum bypass from the two best possible options in Qeshm city. These two options are exhibited in Fig. 3 and identified as A and B. The general specifications of the two A and B options are listed in Table 4. In the meantime, the general length of route $B$ is $12.7 \mathrm{~km}$ and the length which must be made is $7.5 \mathrm{~km}$. The travel time during this route is considered to be $10 \mathrm{~m}$ based on the calculations. Prediction of the number of future accidents due to the traff ic conditions is also based upon Table 5. The traffic volume prediction of Table- 5 is performed by Swedish consulting engineers (Farzipour, 2010). Also, the number of accidents is achieved via Eq. (6). Table 6 lists the number of possibleaccidents in the curves of option A.

According to the distributed forms among the experts, the environmental impacts of each bypass and accordance of each with the city's comprehensive plan were analyzed using Delphi method and in response to the following questions. The following queries were included in the distributed forms -

- With respect to the comprehensive plan of the city, which bypass meets the maximum accordance? (State the response as a number in the interval of 1-20).

- Which of the two bypasses has less environmental adverse effects? (State the response as a number in the interval of 1-20).

- In the design and selection of a bypass, what is the relative importance of each of the travel time, bypass's environmental impact, and construction costs, compliance with the comprehensive plan and the amount of possible accidents in the bypass?

Table 7 illustrates the brief specifications of the two bypasses regarding to the compared parameters. The environmental impacts in Table 7 are achieved via Delphi method. Also, the travel time is estimated with respect to the path length and the plan's velocity. Table 8 gives the short calculations corresponding to the environmental impacts value and compliance with the comprehensive plan of option B.

The two options are compared from the perspective of different metrics. The comparative matrix of options regarding to the compliance with the comprehensive plan, is given in Table 9. The matrix components are evaluated by mutually comparing the mentioned criteria (by dividing the values of the two criteria in each option). It is saying that the above mentioned matrix is achieved by the responses of the third question received from 5 experts and using Delphi method. Table 10 gives the final weights of the criteria in the bypass selection problem.

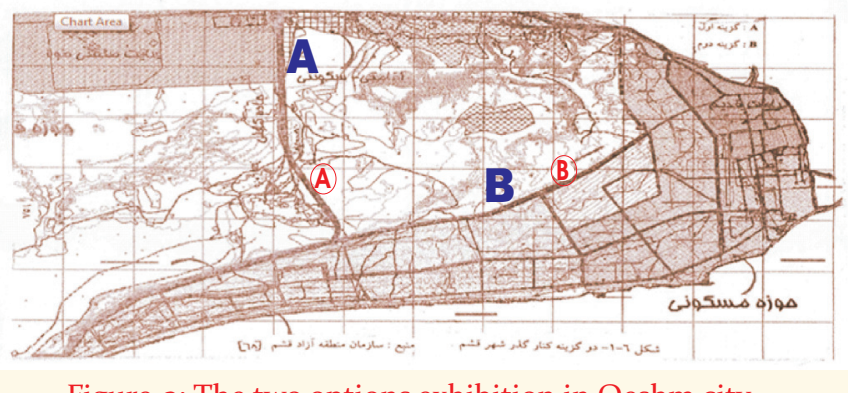

Figure-3: The two options exhibition in Qeshm city

\section{Conclusion:}

A bypass optimization model with the aim reducing the accidents in the vicinity of cities as a consequence was developed using Delphi method and AHP. In this proposed model, the optimization approach was dealt for solving bypasses problems within the best option among the possible and available options of bypass for a particular city. Since the involved criteria and variables in the design of a decision making support system of the bypasses are the combination of the qualitative and quantitative variables, the hierarchical decision making support system capable of separately considering these two classes of variables will be the most appropriate system. In the design of a decision making support system for the bypasses optimization problem, road accidents are the most important involved criterion. For this sake, it is focused here on developing a model as the major issue in the bypasses related decisions. 
Table 4.Specifications of A and B options.

\begin{tabular}{lllllll}
\hline Case & Length $(\mathrm{km})$ & Travel time $(\mathrm{min})$ & Earthworks cost & Manufacturing cost & Acquisition costs & Total costs \\
\hline A & 4.6 & 5 & 1012000000 & 138000000 & 10180000000 & 24992000000 \\
B & 7.5 & 9.52 & 1870000000 & 2750000000 & 1650000000 & 31020000000 \\
\hline
\end{tabular}

Table 5. Prediction of the number accidents caused by the traffic conditions

\begin{tabular}{lllll}
\hline Case & Traffic & $\begin{array}{l}\text { Capacity } \\
\text { volume }\end{array}$ & $\begin{array}{l}\text { Accident } \\
\text { number }\end{array}$ & $\begin{array}{l}\text { Intersection } \\
\text { number }\end{array}$ \\
\hline A & 4000 & 1400 & 2.24 & 2 \\
B & 5500 & 1350 & 2.42 & 2 \\
\hline
\end{tabular}

Table 6 . The number of possible accidents in the curves.

\begin{tabular}{llllll}
\hline $\begin{array}{l}\text { Curve } \\
\text { curve }\end{array}$ & $\begin{array}{l}\text { Degree of } \\
\text { curve* }^{*}\end{array}$ & $\begin{array}{l}\text { Length } \\
\text { of curve }\end{array}$ & $\begin{array}{l}\text { Traffic } \\
\text { volume }\end{array}$ & $\begin{array}{l}\text { Accident } \\
\text { rate }\end{array}$ & $\begin{array}{l}\text { Accident } \\
\text { number }\end{array}$ \\
\hline 1 & 0.67 & 1.73 & 1.46 & 5 & 12.66 \\
2 & 4.55 & 0.6 & 1.46 & 5 & 4.6 \\
3 & 0.6 & 1.2 & 1.46 & 5 & 8.79
\end{tabular}

* These information are collected from the engineering unit of Qeshm free zone organization [10].

Table 7.Brief specifications of the two bypasses regarding to the compared parameters

\begin{tabular}{lllllll}
\hline $\begin{array}{l}\text { Case } \\
\text { (m) }\end{array}$ & Travel & \multicolumn{3}{l}{$\begin{array}{l}\text { Accident Manufact. Environ. According } \\
\text { number }\end{array}$} & cost & Inter- \\
effects & to master & number \\
\hline A & 5 & 14.9 & 24.992 & 6 & 4 & 2 \\
B & 10 & 19.52 & 13.02 & 16 & 14 & 2 \\
\hline
\end{tabular}

Table-8: Calculations corresponding to the environmental impacts value \& compliance with the comprehensive plan of option B.

\begin{tabular}{llcll}
\hline Period & $\begin{array}{l}\text { Average of } \\
\text { environ. } \\
\text { effects }\end{array}$ & $\begin{array}{l}\text { Number of } \\
\text { commenters }\end{array}$ & $\begin{array}{l}\text { Average of } \\
\text { master plan } \\
\text { according }\end{array}$ & $\begin{array}{l}\text { The number } \\
\text { commenters }\end{array}$ \\
\hline First & 16 & 8 & 13.5 & 8 \\
Second 18 & 8 & 14.5 & 8 \\
Third & 15 & 7 & 13.9 & 7 \\
Forth & 15 & 8 & 14 & 8 \\
\hline
\end{tabular}

\section{References:}

Ayati, E. (2005): The cost of traffic accident in Iran. No. 345, Pub. by: Ferdowsi University of Mashhad.

Bendsen, S. (2017): The Danish Road Directorate Traffic Management Centre, Traffic Management Centre (TMC), The Danish Road Directorate. Pub. by: Nordic Road Association (NVF).

Christopher, P. \& Sorin, D. (2011): The impacts of the new public management in Europe: a meta-analysis. Pub. by: Coordinating for Cohesion in the Public Sector of the Future.

Farzipour, H. (2010): Check the status of traffic safety in 18th district of Tehran. Traffic Studies Report. Pub. by: Tehran Traff ic \& Transportation organization, No. 15,16.

Pates, G. (1999): Improving Small City Highways: New Techniques for Improving Safety and Livability Through Technology
Table 9. Comparative matrix of the options

\begin{tabular}{|c|c|c|c|c|}
\hline Matrix type & Matrix C & ompone & ents & \\
\hline $\begin{array}{l}\text { Compare of } \\
\text { environmental impact }\end{array}$ & $\left|\begin{array}{ll}1 & 8 / 3 \\
8 / 3 & 1\end{array}\right|$ & $\Rightarrow \mid$\begin{tabular}{l|l}
0.2 \\
\hdashline & 0.7
\end{tabular} & $\begin{array}{r}2727 \\
7273\end{array}$ & \\
\hline $\begin{array}{l}\text { Compare of } \\
\text { Manufacturing cost }\end{array}$ & $\mid \begin{array}{c}1 \\
31.02 \\
24.992\end{array}$ & $\begin{array}{c}.9922 \\
1.02 \\
1\end{array} \mid$ & $\Rightarrow \mid \begin{array}{l}0 \\
0 .\end{array}$ & $.5538 \mid$ \\
\hline $\begin{array}{l}\text { Compare of } \\
\text { Accident number }\end{array}$ & $\begin{array}{c}1 \\
\underline{14.91} \\
19.52\end{array}$ & $\begin{array}{c}\frac{9.52}{14.9} \\
1\end{array} \mid$ & $\Rightarrow \mid \begin{array}{l}0 \\
0 .\end{array}$ & 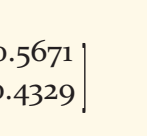 \\
\hline $\begin{array}{l}\text { Compare of } \\
\text { Travel time }\end{array}$ & $\begin{array}{cc}1 & \underline{10} \\
5 & 5 \\
10 & 1\end{array}$ & $\Rightarrow$ & $\begin{array}{l}0.666 \\
0.333\end{array}$ & \\
\hline $\begin{array}{l}\text { Compare of } \\
\text { intersection number }\end{array}$ & $\begin{array}{ll}1 & \underline{2} \\
\underline{2} & 2 \\
2 & 1\end{array}$ & 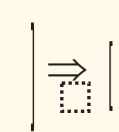 & $\begin{array}{l}05 \\
05\end{array}$ & \\
\hline $\begin{array}{l}\text { Comparison } \\
\text { matrix criteria }\end{array}$ & \begin{tabular}{|cc}
1 & 0.8 \\
1.25 & 1 \\
$\frac{14}{8}$ & \\
$\frac{14}{8}$ & 1.4 \\
1 & 0.8
\end{tabular} & 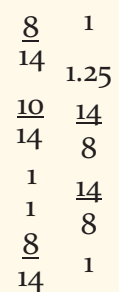 & $\vec{\Rightarrow}$ & $\left|\begin{array}{l}0.1481 \\
0.1852 \\
0.2593 \\
0.2593 \\
0.1481\end{array}\right|$ \\
\hline
\end{tabular}

Table-10:Final weights of the criteria in bypass selection problem

Case According Environ. Manufact Accident Travel Final to master effects cost number time charge plan

\begin{tabular}{lllllll}
\hline A & 0.0329 & 0.0505 & 0.1437 & 0.1447 & 0.0988 & 0.4731 \\
B & 0.1145 & 0.1347 & 0.1158 & 0.1124 & 0.0495 & 0.5269 \\
\hline
\end{tabular}

Transfer. Sixth National Conference on Transportation Planning for Small and Medium-Sized Communities, TRB.

Saaty, T.L. (1980): The Analytic Hierarchy Process: Planning, Priority Setting, Resource Allocation. Pub. by: McGrawHill, California. P. 287.

US.FHA (United States. Federal Highway Administration) (1980): SH-13 Reconstruction and Relocation Through Rifle: Environmental Impact Statement. Pub by: Northwestern University.

Vockrodt, B.A. (1967): The Economic Effects of a Highway Change on Faribault, Minnesota. Pub. by: Minnesota Department of Highways, St. Paul.

Willumsen, L. G. (1981): Simplified transport models based on traffic counts. Transportation, 10(3):257-278. 